\title{
CORRIGENDUM
}

\section{Combining decidability paradigms for existential rules. Theory and Practice of Logic Programming - CORRIGENDUM}

\author{
GEORG GOTTLOB, MARCO MANNA and ANDREAS PIERIS
}

Figure 3 was left out in the article (Gottlob et al. 2013). The figure that is given there as figure 3 should in fact be figure 4 . Further, the reference to figure 3 on the $4^{\text {th }}$ line of page 889 should be a reference to figure 4 . The correct figure 3 (missing in the paper) is supplied below. We apologise for this error.

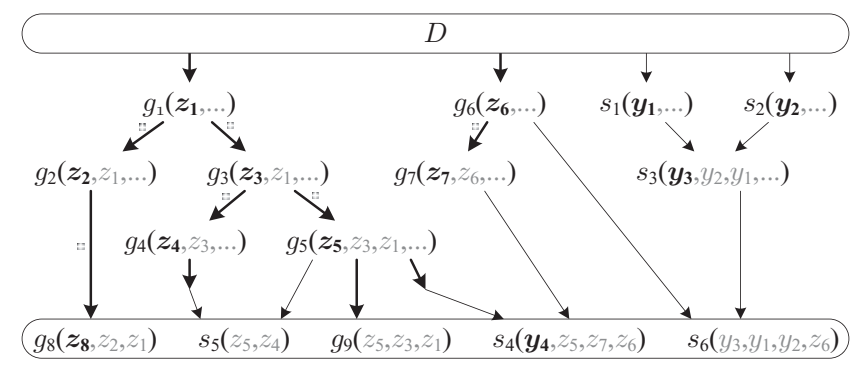

\section{References}

Georg Gottlob, Marco Manna and Andreas Pieris (2013). Combining decidability paradigms for existential rules. Theory and Practice of Logic Programming, vol 13, pp 877-892. doi:10.1017/S1471068413000550. 